atoms give 38 , of which six must be used for the halogens leaving 32 for the metallic cluster.

From the agreement between theory and observation the conclusion is drawn that "electron in a box" theory can be useful in understanding metal atom clusters, its simplicity being particularly attractive.

\footnotetext{
* This research was supported by the Chemical Directorate of the U.S. Air Force Office of Scientific Research, Grant No. AF-AFOSR-245-65.

1 F. A. Cotton and T. E. Haas, Inorg. Chem. 3, 10 (1964).

2 R. V. Lindsey, Jr., G. W. Parshall, and U. G. Stolberg, Inorg. Chem. 5, 109 (1966).
}

\section{ESR of Alkali Metal Dinitrobenzene Salts in Dimethoxyethane DME*}

\author{
Chi-yuan Ling and Julien Gendell \\ Department of Chemistry, University of Michigan \\ Ann Arbor, Michigan
}

(Received 20 July 1966)

$\mathbf{R}^{\mathrm{E}}$ ECENTLY Symons ${ }^{1}$ reported that in THF the sodium and potassium salts of $m$-dinitrobenzene show two different nitrogen hyperfine splittings, as well as different proton splittings from protons which are equivalent in the free radical ion, whereas the rubidium and cesium salts show inequivalence in the proton splittings at low temperatures and equivalence at high temperatures with just one large nitrogen splitting. Previously, Ward ${ }^{2}$ reported that the sodium salt of $m$-dinitrobenzene in DME shows two inequivalent nitrogen splittings but equivalent proton splittings.

We would like to report the results of our investigation of alkali metal satls of $m$-dinitrobenzene in DME and some results for $o$-dinitrobenzene and nitrobenzene salts as well. Our results for $m$-dinitrobenzene in DME given in Table I are, in general, similar to those of Symons in THF, but we do not observe any inequivalence in the protons 4 and 6 at low temperatures for the cesium salt; we believe that in the case of the cesium salt at room temperature, it is best to describe the nitrogens as a motionally averaged equivalent set.

For each salt the alkali-metal splittings decrease with decreasing temperature. For the sodium salt the sodium splitting which is $0.29 \mathrm{G}$ at room temperature decreases to $0.18 \mathrm{G}$ at $-50^{\circ} \mathrm{C}$. The potassium splitting decreases from 0.21 to $0.13 \mathrm{G}$, and the cesium splitting from 2.46 to $2.04 \mathrm{G}$, over this temperature range. We have observed a similar temperature dependence for the alkali metal salts of $o$-dinitrobenzene and nitrobenzene. In addition, for each alkali metal, the metal hyperfine splitting is of the same magnitude in the salts of $m$-dinitrobenzene, $o$-dinitrobenzene, and nitrobenzene.

On cooling the Cs salt, the hyperfine lines broaden, and at $-60^{\circ} \mathrm{C}$ a small nitrogen splitting of about $0.25 \mathrm{G}$ can be resolved. The other nitrogen splitting is now 8.9 $\mathrm{G}$, and even though two inequivalent nitrogens are observed at $-60^{\circ} \mathrm{C}$, we still observe an equivalent pair of protons.

Cation motion from one nitro group to the other, or cation motion which rotates the nitro groups in and out of the molecular plane, could account for these facts. Cation size, temperature, and the distance of separation of the nitro groups will determine whether or not the nitrogens are, on the average, equivalent or inequivalent. In $o$-dinitrobenzene the nitro groups are closer, and we might expect averaging to occur at lower temperatures and with smaller-size cations. We observe equivalent nitrogen and proton splittings along with alkali metal splittings for the potassium and cesium salts of $o$-dinitrobenzene, even at low temperatures. In the case of the lithium and sodium salts at low temperatures, we detect evidence that the nitrogens become inequivalent. The observed splittings for the cesium salt of $o$-dinitrobenzene at $-40^{\circ} \mathrm{C}$ are given in Table II.

Slow cation motion in the case of the cesium salt of $m$-dinitrobenzene can result in equivalent protons and inequivalent nitrogens, since the difference between the nitrogen splittings is large, but the sodium and potassium salt data indicate that the difference between the proton splittings is small. If the rate of cation motion between the nitro groups is very fast, the normal five-line nitrogen pattern results, but a slower rate can broaden out the $m_{N}= \pm 1$ lines and lead to a three-line pattern with twice the splitting. ${ }^{3}$ It seems to us that when the largest hyperfine splitting in the molecule is so modulated, it is best to describe the molecule as containing a motionally averaged equivalent set. We have therefore described the room-temperature $m$-di-

TABLE I. Hyperfine-splitting constants of $m$-dinitrobenzene at room temperature in gauss.

\begin{tabular}{|c|c|c|c|c|c|c|c|}
\hline & $a_{\mathrm{E}(5)}$ & $a_{\mathrm{H}(2)}$ & $a_{\mathrm{B}(4)}$ & $a_{\mathbf{H}(6)}$ & $a_{\mathrm{N}(1)}$ & $a_{\mathrm{N}(3)}$ & $a_{m}^{b}$ \\
\hline $\begin{array}{l}\text { Na salt-DME } \\
\mathrm{K} \text { salt-DME } \\
\text { Cs salt-DME } \\
\text { DME electrolysis } \\
\text { Acetonitrile electrolysis }\end{array}$ & $\begin{array}{l}1.10 \\
1.10 \\
1.08 \\
1.12 \\
1.08\end{array}$ & $\begin{array}{l}3.30 \\
3.10 \\
3.16 \\
2.95 \\
3.11\end{array}$ & $\begin{array}{l}3.85 \\
3.84 \\
4.24 \\
4.66 \\
4.19\end{array}$ & $\begin{array}{l}4.45 \\
4.55 \\
4.24 \\
4.66 \\
4.19\end{array}$ & $\begin{array}{l}9.85 \\
9.00 \\
4.66 \\
4.20 \\
4.68\end{array}$ & $\begin{array}{l}0.29 \\
0.22 \\
4.66^{\circ} \\
4.20 \\
4.68\end{array}$ & $\begin{array}{l}0.29 \\
0.21 \\
2.46\end{array}$ \\
\hline
\end{tabular}

Ayperfine splittings assigned in agreement with Maki and Geske. For the

- Nitrogens treated as equivalent (see text). $\mathrm{Na}$ and $\mathrm{K}$ salt the assignment of $a_{\mathrm{H}(4)}-a_{\mathrm{H}(\theta)}$ and $a_{\mathrm{N}(1)}-a_{\mathrm{N}(2)}$ is arbitrary.

d A. H. Maki and D. H. Geske, J. Chem. Phys, 33, 825 (1960). 
TABLE II. Hyperfine-splitting constants of $o$-dinitrobenzene in gauss.

\begin{tabular}{lcccc}
\hline & $a_{\mathrm{H}(3)}-a_{\mathrm{H}(\mathrm{b})}$ & $a_{\mathrm{H}(1)}-a_{\mathrm{H}(\mathrm{b})}$ & $a_{\mathrm{N}(1)}-a_{\mathrm{N}(2)}{ }^{\mathrm{n}}$ & $a_{\mathrm{CB}}$ \\
\hline Cs salt-DME, & 0.43 & 1.64 & 3.17 & 2.92 \\
$\quad-40^{\circ} \mathrm{C}$ & & & & \\
DME electrolysis & 0.21 & 1.71 & 2.79 & \\
Acetonitrile & 0.42 & 1.63 & 3.22 & \\
$\quad$ electrolysis & & & & \\
\hline
\end{tabular}

a Hyperfine splittings assigned in agreement with Maki and Geske. See Ref. c. b Room temperature.

- Room temperature. See Ref. d of Tabje I.

nitrobenzene cesium salt in this fashion, and such a description leads to an interesting comparison with the splittings obtained in acetonitrile. In the $m$-dinitrobenzene free ion, the larger-proton triplet splitting and the nitrogen splitting vary sizeably with change in solvent. ${ }^{4}$ If one uses the DME electrolysis data as a base, the increased solvation in acetonitrile has about the same effect on the splitting as association with the cesium cation in DME.

Similarly, the smaller proton triplet splitting and the nitrogen splitting in 0 -dinitrobenzene vary greatly with solvent, ${ }^{4}$ and inspection of Table II shows very similar splittings for $o$-dinitrobenzene in acetonitrile and the cesium salt at $-40^{\circ} \mathrm{C}$ in DME.

* Supported by American Chemical Society Petroleum Research Fiund.

${ }^{1}$ M. C. R. Symons, Symposium on Electron Spin Resonance Spectroscopy, Michigan State University, August 1966 (preprint); J. Phys. Chem. (to be published).

${ }_{2}^{2}$ R. L. Ward, J. Chem. Phys. 36, 1405 (1962).

${ }^{3} \mathrm{~J}$. H. Freed and G. K. Fraenkel, J. Chem. Phys. 41, 699 (1964)

${ }^{4}$ P. H. Rieger and G. K. Fraenkel, J. Chem. Phys. 39, 609 (1963).

\section{Magnetism and Bonding in $\mathrm{KCuCl}_{3}{ }^{*}$}

G. J. MaAss, B. C. Gerstein, AND R. D. Wrulett $\dagger$

Institute for Atomic Research and Department of Chemistry Iowa State University, Ames, Iowa

(Received 31 May 1966)

CONSIDERABLE interest in $\mathrm{KCuCl}_{3}$ and other $U$ compounds containing discrete planar $\mathrm{Cu}_{2} \mathrm{Cl}_{6}=$ dimers has been aroused by preliminary magnetic studies and x-ray structural determinations. ${ }^{1}$ As part

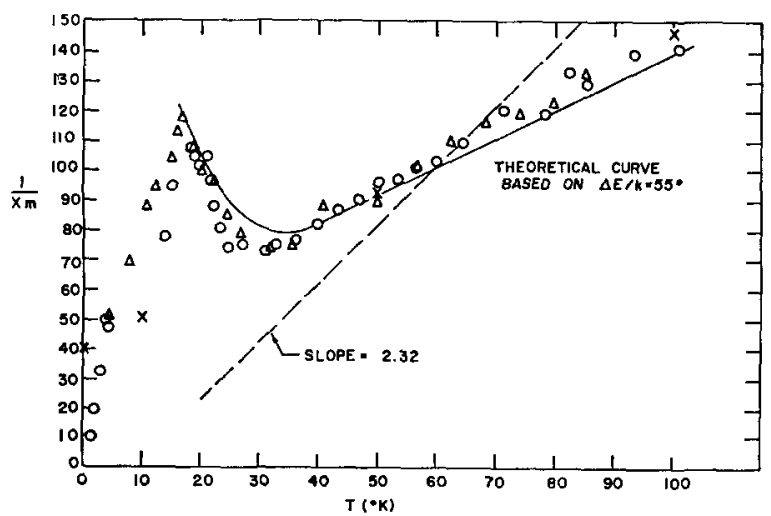

FIG. 1. Reciprocal molar susceptibility of the $\mathrm{K}_{2} \mathrm{Cu}_{2} \mathrm{Cl}_{6}$ dimer. $O$, Cooling data; $\Delta$, heating data; $X$, least-squares points.

of a program involved with the investigation of bonding in alkali-metal-halide-copper-halide double salts the low-temperature magnetic susceptibility and roomtemperature electron spin resonance of $\mathrm{KCuCl}_{\mathbf{3}}$ powder have been measured by the authors. The susceptibility was measured using an inductance technique. The mutual inductance bridge and cryostat systems for the susceptibility work have been described previously. ${ }^{2,3}$ A Strand $602 \mathrm{~B} / \mathrm{X} \mathrm{X}$-band spectrometer was used for the spin resonance measurements.

The preparation of $\mathrm{KCuCl}_{3}$ has been described. ${ }^{1}$ The chemical analysis was done by J. O'Laughlin and $\mathrm{J}$. Connelly of this laboratory, using both standard "wet" methods and atomic absorption. Table I gives the results of the chemical analysis. The lattice constants were determined by J. Ugro of this Chemistry Department and were identical, to within experimental error, to those reported by Willett. ${ }^{1}$

Figure 1 shows a plot of the reciprocal molar susceptibility versus temperature. In this plot, $X m$ is the susceptibility per mole of $\mathrm{K}_{2} \mathrm{Cu}_{2} \mathrm{Cl}_{6}$. This unit of molecular weight was chosen because the $\mathrm{Cu}-\mathrm{Cu}$ spin interaction in the $\mathrm{Cu}_{2} \mathrm{Cl}_{6}=$ dimer is of primary interest. Experimentally, the slope of this plot in the linear region is 1.06 . The dashed line with slope of 2.32 indicates what the slope of the linear region would be if the $\mathrm{KCuCl}_{3}$ monomer with $S=\frac{1}{2}$ were the contributing magnetic species.

The molecular orbital scheme of Willett and Rundle ${ }^{4}$

Table I. Purity of $\mathrm{KCuCl}_{3}$.

\begin{tabular}{|c|c|c|c|c|}
\hline Component & $\mathrm{K}$ & $\mathrm{Cu}$ & $\mathrm{Cl}$ & $\begin{array}{l}\text { Principal } \\
\text { impurity }\end{array}$ \\
\hline \multirow[t]{2}{*}{ Theoretical composition } & \multirow[t]{2}{*}{$18.71 \%$} & \multirow[t]{2}{*}{$30.40 \%$} & \multirow[t]{2}{*}{$50.89 \%$} & $0 \%$ \\
\hline & & & & $\mathrm{Fe}$ \\
\hline $\begin{array}{l}\text { Actual composition (analytical } \\
\text { average) }\end{array}$ & $18.50 \%$ & $30.00 \%$ & $51.50 \%$ & $0.0019 \%$ \\
\hline
\end{tabular}

